\title{
Changes of Serum Retinol Binding Protein 4 Levels Following 8 Weeks
}

\author{
Moderate Aerobic Exercise
}

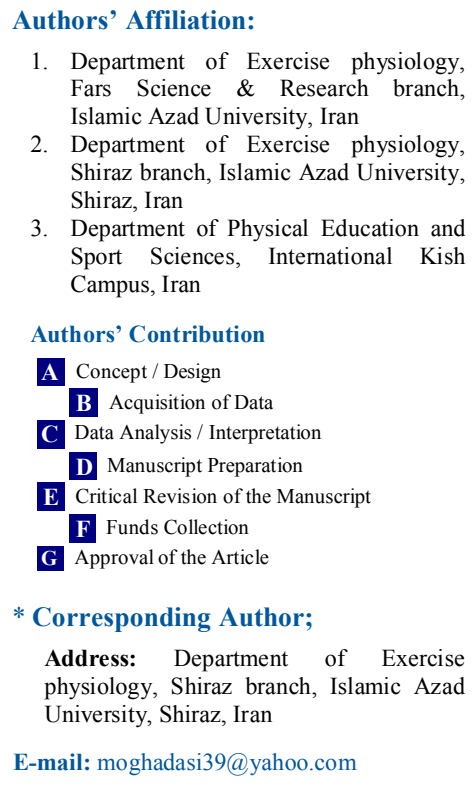

2. Department of Exercise physiology, Shiraz branch, Islamic Azad University, Shiraz, Iran

3. Department of Physical Education and Sport Sciences, International Kish Campus, Iran

Authors' Contribution

A Concept/Design

B Acquisition of Data

C Data Analysis / Interpretation

D Manuscript Preparation

E Critical Revision of the Manuscrip

F Funds Collection

G Approval of the Article

\footnotetext{
* Corresponding Author;

Address: Department of Exercise physiology, Shiraz branch, Islamic Azad University, Shiraz, Iran

E-mail: moghadasi39@yahoo.com
}

Received: Nov 25, 2012

Accepted: May 05, 2013

Available Online: May 25,2013

\author{
Narges Ahmadi ${ }^{1 \text { ABG }}$; Mehrzad Moghadasi ${ }^{2 \text { ACDG }}$, PhD; Reza Nuri ${ }^{3 \text { ADG }}$, PhD
}

\begin{abstract}
Purpose: The purpose of this study was to examine the effects of 8 weeks moderate intensity aerobic exercise on serum retinol binding protein 4 (RBP4) levels in female athletes.

Methods: Twenty female karate athletics were randomly assigned to one of the exercise group $(n=10)$ or control group $(n=10)$. The training group performed endurance training 3 days a week for 8 weeks at an intensity corresponding to 50-60\% individual maximum oxygen consumption for 45 min.
\end{abstract}

Results: Body mass and body mass index increased $(P<0.05)$ after 8 weeks aerobic exercise compared to the control group. For waist to hip ratio (WHR), body fat percentage and maximal oxygen consumption there were no significant differences between the exercise group and the control group. There were virtually no changes in body fat percentage, fasting glucose, insulin, insulin resistance and RBP4 levels after 8 weeks training.

Conclusion: Serum RBP4 level was not affected by 8-week moderate aerobic exercise in female athletes.

Key Words: RBP4; Aerobic Exercise; Female Athletes; Insulin Resistance

\section{INTRODUCTION}

$\mathrm{R}$ etinol binding protein 4 (RBP4), another member of the lipocalin family, has recently been added to the list of adipokines that may link obesity with insulin resistance and type 2 diabetes ${ }^{[1,2]}$. RBP4 is a newly discovered fat derived adipokine that specifically binds to retinol ${ }^{[3]}$ and transthyretin ${ }^{[4]}$. In fact, elevated serum RBP4 levels were associated with the components of metabolic syndrome in insulin-resistant subjects ${ }^{[2]}$. Transgenic over expression of RBP4 or injection of recombinant RBP4 decreases insulin sensitivity in normal mice. In contrast, normalization of RBP4 levels in obese mice restores insulin sensitivity ${ }^{[1]}$. In addition, Seo et $\mathrm{al}^{[5]}$ demonstrated an association between RBP4 levels and non-alcoholic fatty liver disease.

Exercise has been shown to have beneficial effects on obesity, type 2 diabetes, and the metabolic syndrome. Several studies exploring the effects of exercise on circulating RBP4 levels have resulted in inconsistent findings. Circulating RBP4 did not change ${ }^{[6,7]}$, decreased ${ }^{[8-10]}$ or increased ${ }^{[11]}$ in response to exercise. For example, Cho et al ${ }^{[6]}$ reported that there was no significant change in RBP4 levels in obese women after 12 weeks moderate exercise training, while Lim et al ${ }^{[8]}$ indicated that RBP4 levels decrease after 10 weeks exercise in middle-aged women.

This study result showed that RBP4 levels were associated with obesity profiles and insulin resistance, thus we hypothesized that exercise training would reduce the adipose tissue, insulin resistance and RBP4 concentrations; therefore, we investigated the effects of 8 weeks of moderate aerobic exercise on body composition, insulin resistance and RBP4 concentrations in female athletes. 


\section{METHODS AND SUBJECTS}

\section{Subjects:}

Twenty female karate athletics $(24.3 \pm 4.8$ years; mean \pm SD) participated in this study. All the subjects were asked to complete a personal health and medical history questionnaire, which served as a screening tool. The subjects were given both verbal and written instructions outlining the experimental procedure, and written informed consent was obtained. Our participants were nonsmokers and none of them had any disease. All the subjects completed the 3-day diet recall forms and were instructed to maintain their normal physical activity and dietary habits throughout the study. The subjects were randomly assigned to one of either the exercise group $(n=10)$ or control group $(\mathrm{n}=10)$. The study was approved by the Islamic Azad University, Fars Science \& Research branch Ethics Committee.

\section{Exercise training:}

The 8 weeks exercise training program included 3 running sessions per week. The intensity of exercise was customized for each subject based on the relationship between heart rate and oxygen uptake measured at baseline. During the 8 weeks intervention, the subjects were trained for $45 \mathrm{~min}$ per session at a heart rate corresponding to $50-60 \%$ of the maximal oxygen uptake measured at baseline. Each participant wore a heart rate monitor (Beurer, PM70, Germany) to ensure accuracy of the exercise level. Subjects performed the exercise training besides their karate team training.

\section{Measurements:}

Anthropometric and body composition measurements: Height and body mass were measured, and body mass index (BMI) was calculated by dividing body mass $(\mathrm{kg})$ by height $\left(\mathrm{m}^{2}\right)$. Waist circumference was determined by obtaining the minimum circumference (narrowest part of the torso, above the umbilicus) and the maximum hip circumference while standing with their heels together. The waist to hip ratio (WHR) was calculated by dividing waist $(\mathrm{cm})$ by hip circumference $(\mathrm{cm})^{[11]}$. Body fat percentage was assessed by skinfold thickness protocol. Skinfold thickness was measured sequentially, in triceps, suprailiac, and thigh by the same investigator using a skinfold caliper (Harpenden, HSK-BI, British Indicators, West Sussex, UK) and a standard technique ${ }^{[11]}$.

Measurement of $\mathrm{VO}_{2 \max }$ : $\mathrm{VO}_{2 \max }$ was determined by Rockport one-mile fitness walking test. In this test, an individual walked 1 mile as fast as possible on a track surface. Total time was recorded and HR was obtained in the final minute ${ }^{[1]} . \mathrm{VO}_{2 \max }$ was calculated using formula ${ }^{[11]}$

\section{Biochemical analyses:}

Fasted, resting morning blood samples $(10 \mathrm{ml})$ were taken at the same time before and after 8 weeks intervention. For menstrual status, all the participants were menstruating regularly and defined as eumenorrheic (28- to 32-day menstrual cycles during the previous year); all testing was performed during the follicular phase of the menstrual cycle. All the subjects fasted at least for 12 hours and a fasting blood sample was obtained by venipuncture. Serum obtained was frozen at $-80^{\circ \mathrm{C}}$ for subsequent analysis. The serum RBP4 level was measured in duplicate using an enzyme-linked immunosorbent assay (ELISA) kits (Casabio Biotech Co. LTD.; China). The sensitivity of kit was $0.1 \mu \mathrm{g} / \mathrm{ml}$. Serum glucose was determined by the enzymatic (GOD-PAP, Giucose Oxidase-Amino Antipyrine) colorimetric method (Pars Azmoun, Tehran, Iran). The intra and inter-assay coefficients of variation for glucose were $<1.3 \%$ and a sensitivity of 5 $\mathrm{mg} / \mathrm{dl}$. The serum insulin level was measured by an electrochemiluminescence immunoassay (ECLIA) and the insulin resistance index was calculated according to the homeostasis model assessment (HOMA-IR) which correlates well with the euglycemic hyperinsulinemic clamp in people with diabetes ${ }^{[12]}$.

\section{Statistical analysis:}

Results were expressed as the mean $\pm \mathrm{SD}$ and distributions of all variables were assessed for normality. Paired t test was used to compute mean $( \pm \mathrm{SD})$ changes in the variables in control and training group pre- and after the intervention. A two-way ANOVA was used to determine if significant $(P \leq 0.05)$ differences existed among the groups for biochemical variables between before and after exercise training. 
Table 1: Anthropometric and metabolic characteristics (mean \pm SD) of the subjects before and after training

\begin{tabular}{|c|c|c|c|c|}
\hline \multirow{2}{*}{ Parameter } & \multicolumn{2}{|c|}{ Control (Mean \pm SD) } & \multicolumn{2}{|c|}{ Training $($ Mean \pm SD $)$} \\
\hline & Pre-training & Post-training & Pre-training & Post-training \\
\hline Body mass (Kg) & $57.8(8.4)$ & $57.9(8.4)$ & $55.1(9.1)$ & $57.4(9.1)^{* \dagger}$ \\
\hline Body mass index $\left(\mathrm{Kg} / \mathrm{m}^{2}\right)$ & $21.4(3.0)$ & $21.4(3.0)$ & $21.3(2.8)$ & $22.2(2.6)^{* \dagger}$ \\
\hline Body fat $(\%)$ & $17.3(5.0)$ & $17.8(5.2)$ & $18.6(3.3)$ & $19.0(3.0)$ \\
\hline Waist to hip ratio & $0.74(0.05)$ & $0.75(0.05)$ & $0.73(0.04)$ & $0.70(0.03)$ \\
\hline $\mathrm{VO}_{2 \max }\left(\mathrm{ml} \cdot \mathrm{Kg}^{-1} \cdot \mathrm{min}^{-1}\right)$ & $47.7(3.5)$ & $47.9(3.4)$ & $47.5(3.8)$ & $48.2(2.8)$ \\
\hline
\end{tabular}

*: $P<0.05$ for between-group differences; $\dagger: P<0.05$, pre-training $v s$. post-training values; SD: Standard Deviation

The relationships between variables in the training groups were determined using Spearman correlation with body mass, BMI, body fat percentage and HOMA-IR at baseline and after 8 weeks exercise.

test. The level of significance in all statistical analyses was set at $P \leq 0.05$. Data analyses were performed using SPSS software for windows (version 13, SPSS, Inc., Chicago, IL).

\section{RESULTS}

Physical and physiological characteristics of the subjects at baseline and after training are presented in Table 1. Before the intervention, there were no significant differences in any of variables among the two groups. Body mass and BMI increased $(\mathrm{P}<0.05)$ after 8 weeks aerobic exercise compared to the control group. For WHR, body fat percentage and maximal oxygen consumption there were no significant difference between the exercise group and the control group.

RBP4 $(\mathrm{F}=0.3, P=0.8)$, fasting glucose $(\mathrm{F}=1, P=0.4)$, fasting insulin $(\mathrm{F}=0.4, P=0.8)$, and HOMA-IR $(\mathrm{F}=0.7$, $P=0.5)$ did not change in the exercise training compared with the control group (Table 2). No significant relationships were observed between RBP4

\section{DISCUSSION}

RBP4, has recently been identified as a novel adipokine associated with obesity, type 2 diabetes and the metabolic syndrome ${ }^{[1,2,13]}$. The effects of exercise training on serum RBP4 is still unclear. The purpose of this study was to examine the effects of 8 weeks moderate aerobic exercise on serum RBP4 levels in female athletes. Our results showed that RBP4 levels at baseline were lower in female athletes (median 11.6 [range 3.7-16.7 $\mu \mathrm{g} / \mathrm{ml}$ ]) than in impaired glucose tolerance, type 2 diabetic and healthy subjects. Cho et $\mathrm{al}^{[14]}$ demonstrated median levels of plasma RBP4 concentrations in the impaired glucose tolerance (median 18.9 [range 11.2-45.8 $\mu \mathrm{g} / \mathrm{ml}$ ]), type 2 diabetic patients (median 20.9 [range 9.9-48.5 $\mu \mathrm{g} / \mathrm{ml}$ ) and healthy subjects (median $18.1[9.3-30.5 \mu \mathrm{g} / \mathrm{ml}]$ ). Thus it seems that practicing karate improves levels of RBP4 in females.

Our results are in agreement with previous reports showing that there was no relationship between RBP4

Table 2: Biochemical characteristics (mean $\pm \mathrm{SD}$ ) of the subjects before and after training

\begin{tabular}{|l|cccc|}
\hline \multirow{2}{*}{ Parameter } & \multicolumn{2}{c}{ Control $($ mean \pm SD) } & \multicolumn{2}{c|}{ Training $($ mean \pm SD) } \\
FBS $(\mathbf{m g} / \mathbf{d l})$ & Pre-training & Post-training & Pre-training & Post-training \\
Insulin $(\boldsymbol{\mu} \mathbf{U} / \mathbf{m l})$ & $90.3(8.8)$ & $85.8(8.5)$ & $89.1(2.7)$ & $84.6(7.9)$ \\
HOMA-IR & $8(2.9)$ & $9.6(4)$ & $10.2(4.1)$ & $10.1(2.3)$ \\
RBP4 $(\boldsymbol{\mu} \mathbf{g} / \mathbf{m l})$ & $1.7(0.5)$ & $1.9(0.7)$ & $2.2(0.9)$ & $2(0.5)$ \\
\hline
\end{tabular}

SD: Standard Deviation; FBS: Fasting blood glucose; HOMA-IR: homeostasis model assessment; RBP4: Retinol binding protein 4 
levels and body composition parameters including body mass, BMI and WHR in female athletes. Cho et al ${ }^{[6]}$ indicated that RBP4 levels were not associated with body mass in obese Korean women. Mansouri et al ${ }^{[7]}$ also demonstrated that RBP4 levels were not associated with BMI in young male students. However, this could be attributed to differences in subject populations because our subjects were athletes while non-athlete middle-aged women were participated in the Lim et al study. The results showed that body fat percentage did not significantly change after 8 weeks exercise, thus it seems that the lack of effect of exercise training on RBP4 in the present study might be due to the absence of reductions in body fat percentage. Studies demonstrated that the response of RBP4 to 1 month of exercise training was variable ${ }^{[2]}$, and RBP4 levels were decreased after exercise mainly in the subjects having higher RBP4 levels at baseline ${ }^{[8]}$. Research results showed that the basic level of RBP4 appeared to be the only predictor of after exercise RBP4 concentration ${ }^{[7]}$. Our results demonstrated that RBP4 levels at baseline were lower than the subjects that participated in the Lim et al study, suggesting that athletes might have lower levels of RPB4 than nonathletes.

On the other hand, elevated RBP4 levels have been reported in subjects with insulin resistance and type 2 diabetes ${ }^{[2,6]}$ whereas other studies showed no relationship between circulating RBP4, obesity and insulin resistance ${ }^{[7,15,16]}$. Our results showed that there was no significant relationship between RBP4 levels and insulin resistance determined by HOMA-IR. Cho et al ${ }^{[6]}$ and Mansouri et al ${ }^{[7]}$ also indicated that RBP4 levels were not associated with insulin resistance while, Lim et al ${ }^{[8]}$ showed that there was a positive relationship between RBP4 concentration and insulin resistance. In our study, there was virtually no change in fasting glucose and insulin and HOMA-IR after 8 weeks training. Lim et al ${ }^{[8]}$ however, reported that insulin resistance decreased after 10 weeks exercise training in young and middle-aged women. We had some limitations in this study. We did not measure inflammatory markers and cardiovascular risk factors. Previous studies demonstrated that RBP4 concentrations were associated with inflammatory markers such as C-reactive protein ${ }^{[17]}$ and cardiovascular risk factors such as triglyceride ${ }^{[9]}$, total cholesterol ${ }^{[6]}$ and low density lipoprotein (LDL) cholesterol ${ }^{[6]}$. If we could measure these markers, we could carefully explain the changes of RBP4 concentrations in response to 8 weeks exercise training in female athletes.

\section{CONCLUSION}

RBP4 level associated with obesity profiles and insulin resistance, thus we examined if exercise training would reduce the body fat and insulin resistance and decrease RBP4 concentrations. Our results showed that serum RBP4 levels were not affected by 8 weeks moderate aerobic exercise in female athletes. Additional research is needed to examine our hypothesis.

\section{ACKNOWLEDGMENTS}

The work was supported by grants from the Fars Science \& Research branch, Islamic Azad University. The authors gratefully acknowledge the all subjects whom cooperated in this investigation.

Conflict of interests: None

\section{REFERENCES}

[1] Yang Q, Graham TE, Mody N, et al. Serum retinol binding protein 4 contributes to insulin resistance in obesity and type 2 diabetes. Nature 2005;436:356-62.

[2] Graham TE, Yang Q, Blüher M, et al. Retinol-binding protein 4 and insulin resistance in lean, obese, and diabetic subjects. New Engl J Med 2006;354:2552-63. 
[3] Quadro L, Blaner WS, Salchow DJ, et al. Impaired retinal function and vitamin A availability in mice lacking retinol-binding protein. EMBO J 1999;18:4633-44.

[4] Klöting N, Graham TE, Berndt J, et al. Serum retinol-binding protein is more highly expressed in visceral than in subcutaneous adipose tissue and is a marker of intra-abdominal fat mass. Cell Metab 2007;6:79-87.

[5] Seo JA, Kim NH, Park SY, et al. Serum retinol-binding protein 4 levels are elevated in non-alcoholic fatty liver disease. Clin Endocrinol 2008;68:555-60.

[6] Cho YM, Youn BS, Lee H, et al. Plasma retinol-binding protein-4 concentrations are elevated in human subjects with impaired glucose tolerance and type 2 diabetes. Diabetes Care 2006;29:2457-61.

[7] Mansouri M, Keshtkar A, Hasani-Ranjbar S, et al. The impact of one session resistance exercise on plasma adiponectin and RBP4 concentration in trained and untrained healthy young men. Endocr J 2011;58:861-8.

[8] Lim S, Choi SH, Jeong IK, et al. Insulin-sensitizing effects of exercise on adiponectin and retinol-binding protein-4 concentrations in young and middle-aged women. J Clin Endocrinol Metab 2008;93:2263-8.

[9] Numao S, Sasai H, Nomata Y, et al. Effects of exercise training on circulating retinol-binding protein 4 and cardiovascular disease risk factors in obese men. Obes Facts 2012;5:845-55.

[10] $\mathrm{Ku} \mathrm{YH,} \mathrm{Han} \mathrm{KA,} \mathrm{Ahn} \mathrm{H,} \mathrm{et} \mathrm{al.} \mathrm{Resistance} \mathrm{exercise} \mathrm{did} \mathrm{not} \mathrm{alter} \mathrm{intramuscular} \mathrm{adipose} \mathrm{tissue} \mathrm{but} \mathrm{reduced} \mathrm{retinol-binding} \mathrm{protein-4}$ concentration in individuals with type 2 diabetes mellitus. J Int Med Res 2010;38:782-91.

[11] ACSM; ACSM guidelines for exercise testing and prescription ${ }^{\text {th }}$ ed. Philadelphia: Lippincott, Williams and Wilkins. 2005; Pp: 2130.

[12] Matthews DR, Hosker JP, Rudenski AS, et al. Homeostasis model assessment: Insulin resistance and beta-cell function from fasting plasma glucose and insulin concentrations in man. Diabetologia 1985;28:412-9.

[13] Gavi S, Stuart LM, Kelly P, et al. Retinol-binding protein 4 is associated with insulin resistance and body fat distribution in nonobese subjects without type 2 diabetes. J Clin Endocrinol Metab 2007;92:1886-90.

[14] Cho YM, Youn BS, Lee H, et al. Plasma retinol-binding protein-4 concentrations are elevated in human subjects with impaired glucose tolerance and type 2 diabetes. Diabetes Care 2006;29:2457-61.

[15] Janke J, Engli S, Boschmann M, et al. Retinol-binding protein 4 in human obesity. Diabetes 2006;55:2805-10.

[16] Yao-Borengasser A, Varma V, Bodles AM, et al. Retinol binding protein 4 expression in humans: relationship to insulin resistance, inflammation, and response to pioglitazone. J Clin Endocrinol Metab 2007;92:2590-7.

[17] Qi Q, Yu Z, Ye X, et al. Elevated retinol-binding protein 4 levels are associated with metabolic syndrome in Chinese people. J Clin Endocrinol Metab 2007;92:4827-34. 